\title{
Operationalizing the progression from prospect to customer to evangelist: How marketing operations supports transparency and trust building in the New World of Web 2.0 - Interview with Gary Katz of Marketing Operations Partners
}

\author{
Gary Katz \\ is a visionary and thought leader in the emerging Marketing Operations field. He is a veteran, with more than 20 years of \\ marketing and change management experience in the technology industry in corporate, agency and entrepreneurial positions, \\ where he directed corporate marketing, communications, public relations, lead generation and qualification, investor relations, \\ and employee communications programs. Gary holds a Master's degree in organization development from the University of \\ San Francisco and a Bachelor's degree in public relations from San Jose State University. Gary is past president of the Silicon \\ Valley Chapter, Public Relations Society of America (PRSA), an Accredited Member of PRSA and has been certified as a strategic \\ planning process facilitator by the Institute of Cultural Affairs. He is currently vice president of the Silicon Valley Chapter of the \\ American Marketing Association (AMA), a national board member of the Business Marketing Association (BMA) and a member of \\ the BMA Thought Leadership Committee. He has served as a track chair for the Henry Stewart Marketing Operations Management \\ Symposium since 2005, has frequently spoken and moderated panels on Marketing Operations and Marketing ROI-related \\ topics and has published several articles on Marketing Operations in MarketingProfs, Automate and other publications. In 2006, \\ Gary started Marketing Operations Evangelists, a growing group of leaders dedicated to advancing the profession of Marketing \\ Operations. Gary is the founder and CEO of Marketing Operations Partners.
}

Keywords: marketing operations, marketing ROI, lead management, lead nurturing, sales pipeline, sales funnel

Gary Katz

Marketing Operations Partners, 2079 Fordham Drive, Santa Clara, CA 95051, USA Tel: 408-243-7881 E-mail: gary@mopartners. com

\begin{abstract}
The Internet is a great equalizer in leveling the playing field for buyers and sellers. Today, customers have more power than ever and, together with investors, are holding enterprises to new levels of accountability to deliver on the representations they make to the market. Transparency and trust are intricately intertwined. Web 2.0 amplifies and reinforces this shift from selling to naive prospects to building trusted relationships with savvy customers. While products were once key business differentiators, a slippage in brand loyalty indicates that few companies today can build a sustainable business strategy on technology differentiation alone. The experience a customer has while interacting with the company through each phase of the business relationship is now paramount. Managing customer experience, especially on the Internet, is a tenuous endeavor. Web 2.0 may create some uplift in two-way communication, but it also contributes to increased liability exposure. Anyone - even a company's own disgruntled employees - can use blogs, wikis, forums and other vehicles to circulate information on the Web that can substantially help or hinder an enterprise's credibility. Gary Katz, founder and CEO of Marketing Operations Partners, believes that CMOs, supported by their marketing operations (MO) teams, are in a unique position to help enterprises manage this transition. The evolving discipline of $\mathrm{MO}$ addresses the customer relationship continuum end-to-end - from first touch through outbound marketing to nurturing through the sales funnel, from building customer affinity
\end{abstract}


through voice of the customer and loyalty programs to leveraging that affinity to engaging the most evangelistic customers in the sales and marketing process. In this interview, Katz shares his insights on the areas MO addresses, why it is increasingly important in today's world, and how it can help enterprises deliver on accelerating customer expectations and business objectives.

Journal of Digital Asset Management (2008) 4, 197-212. doi:10.1057/dam.2008.27

MM: We're here with Gary Katz of Marketing Operations Partners.

Gary, would you give us a little background in terms of your professional career?

GK:Yes. I'd be happy to, Michael. I'll work backward, as opposed to forward.

I started Marketing Operations Partners about a year and a half ago. It was a spin-off from another entrepreneurial company I started called

CommPros Group. Basically, the goal of Marketing Operations Partners is to help CEOs extend their tenure, help minimize waste in the marketing function, help allocate resources better and to be able to demonstrate the value of marketing to the overall organization - so that those of us in marketing are not easy budget cuts, and have better career paths, and more job satisfaction.

CommPros Group has evolved into what we like to call an "adoption agency" for orphaned and newborn marketing programs. Those marketing programs that don't get the attention they deserve, and could be of great benefit to companies if they had owners.

I decided to start CommPros Group after spending approximately six years in the corporate world. My last company was ShoreTel - a company in the enterprise IP-telephony/ VoIP space. ShoreTel went through a rebrand from Shoreline Communications under my role as Director of Communications there. I got very involved in a lot of the things that we do in MO today when I was at ShoreTel — including enterprise CRM initiatives, lead management, process mapping, customer reference pipeline development and so on.

Before ShoreTel, I worked for a Japanese company, Aplix Corporation, where I was director of corporate marketing. I was responsible for all international marketing outside the domestic market, Japan. Aplix is a company that had not really seriously entered the US market, and during my year and a half there we entered the US and the European markets, as well as the rest-of-Asia market -
China in particular. Aplix was successful going public on the Mother's Tokyo Stock Exchange before I left.

Before that, for two-and-a-half years I was with Insignia Solutions, a public company traded on the NASDAQ and known for emulationtype software called SoftWindows. They were moving out of that market and into the mobile Java space at that time - for devices like PDAs and embedded devices. I helped them launch what was called the Jeode Platform.

I also was responsible for their investor relations, acting as spokesperson to the company's investors - working with them and keeping them updated on company developments. The highlight of that role was going on financial community road shows with the CEO to help raise money for the company. We actually raised about $\$ 23 \mathrm{~m}$ during that time.

Before that, I had my own business called Katz Business Communications, which still exists as a holding company for my other companies. I was a consultant and had my own clients, working with companies like Finisar Corporation, which is about a half-billion dollar company today in gigabit optics, network test and measurement and so on. I actually launched their public relations (PR) function.

I worked with Marcom firms and PR agencies as a preferred subcontractor. I probably worked with a couple of dozen of them in Silicon Valley. Very recognizable names like Cunningham Communication, Walt \& Company, Hayes Public Relations, Simon-McGarry, KVO and so on.

I was a PR director for a Marcom firm called Bricker Evans, for a couple of years during that time. And I had my own PR firm called Public Relations Solutions in the mid-1980s through to about 1990. I went to school at San Jose State University and earned a Bachelor of Arts degree in PR. I graduated in 1981. I actually went back to school because I was frustrated in PR with the inability of companies to perform very effectively behind the messages they 
communicated. I received a Masters Degree in organization development from the University of San Francisco in 1995; my Masters thesis involved applying a model of organization effectiveness, learning and change management theory to PR and communications management. MM: That clearly demonstrates that you've had lots and lots of experience in many different contexts of marketing organizations.

GK: That's right. Also on the professional association front, I'm past president of the Silicon Valley Chapter of the Public Relations Society of America and currently vice-president of the Silicon Valley Chapter of the American Marketing Association. And now I'm on Pat LaPointe's Thought Leadership Committee for the Business Marketing Association, which comes with a national board seat.

MM: Excellent. This would be a great time to characterize what you currently do with your clients today. What kinds of services or solutions do you bring to your clients today?

GK: What I put together is a team of very senior people, with a breadth of $\mathrm{MO}$ experience. We help companies launch their MO functions or reach the next level of MO maturity. We tend to engage where an objective third-party can bring the most value: $\mathrm{MO}$ assessments, designing and deploying new processes, change management initiatives, best practice insight, MO education and socialization, facilitating collaborative strategic, operational processes and so on.

One of our unique value propositions is the diversity of subject matter expertise our team encompasses. We can effectively operate as a MO think-tank to ensure a breadth of perspectives are weighed and considered as companies move forward in the MO maturity process.

This is especially important because it's overwhelming for most companies to approach MO from a broad and multi-faceted vision. The variety of subject-matter expertise that's required to do the job holistically comes from so many disciplines - quality and manufacturing, customer-experience management, Sales Force automation, organizational change and learning, economics, participatory management, project management and so on.

A lot of companies are trying to tackle $\mathrm{MO}$ by throwing a body or bodies at the problem, resulting in a focus on the symptoms, not the fundamental dysfunction. The hard part is balancing the need to get quick results and manage the company's tolerance for change (and willingness to invest) without compromising the long-term vision. Many companies take an activity-focused approach to $\mathrm{MO}$ - develop a dashboard, create a template and deploy a technology tool. While all of these activities are valuable when applied correctly, they tend to trick us into thinking we are working to a strategic roadmap when we actually may be perpetuating the siloed behaviors we are trying to overcome in the first place.

Even in those companies that have recognized the value of $\mathrm{MO}$, the function is severely underresourced. We live in what I like to call an age of the individual contributor director/VP. I'm aware of dozens of MO leaders at substantial companies with no team whatsoever. It seemed to me that there was an opportunity to provide an outsourced team model in the $\mathrm{MO}$ space to support the teamless or under resourced MO leader. My goal was to pull that together.

I'd seen an outsourced team-based model occur in the PR world. When you go back historically and look at the PR profession, you look back at the founders, who were, initially, in-house. Then at some point, they broke out and became consultants.

Then, ultimately, that evolved into a team approach. Today's PR firm working with large companies is bringing a team to the party with expertise in different areas to solve the problem.

I hadn't seen this occur yet in the MO world, and I saw the opportunity to offer that. Basically, we bring a team that focuses on those things that are hard to do in-house. We come into a company and help to diagnose what's going on from an objective standpoint. Of course, we all know from having worked in-house ourselves, it's hard to have the same objectivity and the same perspective. You're usually trying to survive. You're trying to keep your boss happy. You're trying to be politically effective. It's hard to be as strategic.

So a key value we bring is the ability to accurately diagnose what's really going on, and help companies prioritize what it is that they ought to be focusing on, and put a roadmap of change in place to enable them to move forward in a way that has the most leverage. Not just in 
the short-term, where certainly you want to get the quick wins, so that you can get increasingly more support for your programs — but also in the long-term, in terms of doing those things that create the most waves and have the most leverage to set up for success other key initiatives down the road. Trying to set companies up to with the right precedent from the outset - not just to get those short-term wins, but also to address long-term issues like change management and widespread executive and cross-functional support, is critical.

Then you have to help companies be realistic about where they should start and what they're able to tolerate. But at the same time, to push them a little bit. Otherwise, they're going to stay at the status quo.

We like to say that we're about trying to change the $\mathrm{MO}$ of marketing through MO. Of course the acronym of Marketing Operations and the acronym of Modus Operandi are the same so that's a nice little universal twist.

MM: What do you mean by the "maturity cycle?"

GK: I'm talking about where they are in their MO growth versus other companies. Are they at the beginning? Are they working on the fundamentals? Or are they somewhat along but still in the journey level stages? Or are they quite sophisticated?

Even those companies that are quite sophisticated in the different types of tools that they deploy in $\mathrm{MO}$ - they all have significant areas where they are trying to grow and trying to evolve.

There are companies that are fairly evolved - like Cisco. They still have real pain points in MO. They're not very happy with their measurement process. They're still trying to get a handle on where they are with regard to best practices from companies not necessarily in technology alone - B2B - but also in other industries.

MM: Gary, would you give us what I'll call key trends and developments in marketing? GK: Sure. On the marketing side, of course, we're increasingly living in a more and more transparent world. We've seen companies that are really taking big marketing hits because they weren't transparent, and they were doing things that caused their stakeholders grief, even more than grief it caused them great anger because they were not operating totally above-board.

We've seen examples of this over and over again. Nortel had some challenges with this, for example, a couple of years ago. I guess it was more like three to four years ago. The executives were all really under fire because of some decisions they'd made, in terms of financials and so on.

Sarbanes-Oxley compliance has also changed the nature of how companies communicate with their stakeholders.

The internet has been the great equalizer in terms of leveling the playing field for many companies. Now, big companies especially must be much more accountable. Anybody can put something on the Internet - including their own people - in blogs or forums and so on. Web 2.0 does help accelerate two-way communications to a degree, but also creates more liability exposure.

I think the fact is that the Internet has evolved, and now Web 2.0 is becoming or is actually out there — at least in words — in a very significant way. Some companies are working beyond Web 2.0, and trying to leverage the internet more and more as a thought leadership platform, where they can show their expertise in different areas. Even if it isn't steering people to their core websites.

However, I think that a lot of companies are frankly overemphasizing the internet and trying to do everything on the internet. You can track the web analytics more easily, it's less expensive and so on. I do think companies have lost sight of whether the internet is really where their audience wants to do business with them.

MM: It seems to me, Gary, that when we think about the face of marketing today, there are really several categories that immediately you'll fall into. You're a consumer products and consumer services firm. The web is really about developing awareness and consideration for something that consumers will ultimately buy or engage either at retail or direct mail or something like that.

GK: Absolutely. It's another great channel. Both to reach your audience and to sell to your audience.

MM: Then you've got the B2B, which is really about leads. Right? 
GK: Absolutely. Especially for companies that are in the younger stages of their organizational maturity cycle. Or depending on a robust sales pipeline to meet their financial objectives. MM: Then there's a third group of companies where the web isn't so much about lead generation or engagement with the consumer consideration, but it's really about business services delivery. It's really about interacting and collaborating in a business ecosystem.

GK: That's absolutely right.

MM: With those three things - with consumer engagement and with the idea of creating brand equity - B2B - which is really about leads, and to a lesser extent service - and then, third, it's about self services and other forms of enhanced ways of interacting with customers.

How does the operational aspect of responding to any of those differ?

GK: Well, first of all, I think we need to realize that the customer has power, today. I think there's been a significant shift, as far as that's concerned. It's much easier for a customer to find alternatives to what we have to offer and thus, relationship becomes more and more important. And trust becomes more and more important. Nobody's going to do business for very long with companies that they don't trust, and that they don't feel are taking good care of them.

I think a key part of $\mathrm{MO}$, to our companies and us - is the whole customer experience management side. And also, the profitability of the customer and being able to understand things like, "What is the lifetime customer value of that particular customer? The customer franchise value? Is this a customer that we really should be targeting, based on our business goals?"

I think companies are getting more sophisticated about prospect profiles, market segmentation and so on. I think that MO is certainly an area that can support that, in terms of having good information about the customer and good mechanisms to make sure that what we say as a company is followed through in performance by those people whose actions touch the customer.

The touch points - and making sure that the voice of the customer resonates throughout our organization and that we're responding accordingly — are very, very important today. That would be one area.

In terms of the lead generation side developing those customer relationships from the prospect stage all the way to the evangelist stage, when they become someone who will speak on behalf of your company. Who will be a great reference, who will participate in your case studies and so on.

There's a whole operational nature to your customer relationships, which is very, very valuable in marketing. For a company like ShoreTel, that customer loyalty was probably our major competitive advantage.

So, operationalizing the customer references and being able to actually develop a pipeline of customer references - just like you would develop a sales pipeline - has become an area of increased focus in companies. That's something we do.

MM: I found that to be especially true for companies that are entering a new market or who are creating a new market. Oftentimes the first group of people really to engage work through rationalizing and simplifying a heretofore complex horse pill type of value proposition are those early-stage customers. GK: That's absolutely right. You need those customers in order to have credibility in that market.

MM: Beyond even credibility. It's, "What value do we really bring to the market?"

GK: Exactly — and being able to talk about that value in a way that's specific to that slice of audience.

MM: Well, more importantly, in a way that resonates and connects with the corporate, political and personal realities of buyers.

GK: That's right. And the goods we have to offer, of course.

When I was at ShoreTel, I put in a customer reference process. It was a recognition that I had to feed myself in marketing. Especially in a channel company, it becomes all the more important.

MM: A channel company is one that has resellers, VARs and integrators between you and the customer.

GK: That's exactly right. In that type of company, it's hard to keep tabs on what's going on with the customer. Sales isn't incented to do so after the deal is done. They're more interested 
in new opportunities and new potential customers.

Basically, when I was at ShoreTel, I needed to put that customer reference process in place, in order to feed myself - to be able to have customers for seminars and webinars and PR purposes and so on. Initially, that's why I put the program in.

It evolved in a short time - probably within a year - to where sales became the major benefactor and the major requestor. Like you were saying, they needed references in order to enter into new markets and specific geographic territories, as well. If you understand your pipeline well, then you can help sales get exactly the customer reference they need in order to help them close deals. That is really valuable.

MM: Could you drill down a little more on the operational aspects of a customer-reference pipeline?

GK: Sure.

One of my partners - Dick Heermance is actually the person who put the process in place at ShoreTel in the summer of 2004, and he's actually still running that program. He actually contacts, first, the channel partners - to find out who they believe are the most receptive customers in terms of participating from a reference standpoint. Of course, there are various ways that one might participate as a reference. Anywhere from, "Yes. I'll talk to your prospective customers, but that's all I'll do," all the way to, "I'll fly 300 miles to speak at a tradeshow, on a customer panel on your behalf." That's a really wonderful customer to have.

Really, it takes very good database management in order to accomplish that. There are different approaches. Some companies just use their existing CRM - like in ShoreTel's case, they use Siebel. They pull the information they need out of it, and they actually have developed a fairly sophisticated spreadsheet dashboard for their customer references. Dick is using this sophisticated but low-tech tool based on a spreadsheet.

Now if you want to go higher tech, there are wonderful companies out there, like Boulder Logic. That's a company we partner with that has an ASP model for customer references. That enables you to manage your entire customer reference program online. Everybody can have access to it. It's got the analytics built into it. It's much like the difference between using Excel as a project management platform - which a lot of companies actually do - to using what we call MO management or marketing resource management or enterprise marketing management type of solutions.

MM:You were saying your customer reference management first checked in with your channel partners, to find out who was most receptive and to perhaps make an introduction.

GK: That's right. At that point, he made contact with those companies. He gathered information. Of course, that information - the types of questions he asked — was both in terms of gathering what their willingness was, in terms of being a reference, and how far they would go.

The continuum I mentioned before. Gathering the core information of what might be interesting to different audiences, with the ultimate goal being a story the press would care about publishing.

Answering the questions that a case study would address, for instance. Engaging with those people and lining them up to participate in whatever ways that they're willing to offer. Effectively qualifying them for participation in different aspects of the company's sales and marketing efforts.

That's much like what a telemarketer or inside sales person or telesales person might do when leads come in. This is the same approach. The only reason Dick went to the channel partner first is that when I was there we had 1,200 customers. There are a lot more now. And 150 channel partners. It's a lot easier to call 150 channel partners, first, than 1,200 customers without knowing where to prioritize.

MM: Clearly, the channel partner wants to highlight one of their better customers. If that customer shares the goods, then the channel partner looks like a hero.

GK: Absolutely. A good channel partner always benefits in these scenarios. Especially from those marketing activities that become public - like webinars and case studies and news studies. They're always mentioned as part of it.

If you coach the customer properly, they're going to talk about not just the value proposition of the ShoreTel Solution, but what the channel partner brought to the party in order to help. If you ask those questions properly, then all of that's going to come out 
and benefit the channel partner - who oftentimes is not particularly strong in marketing. And it benefits a lot.

Actually, at ShoreTel, we were talking about not just the customer references, but another area of operationalizing that you mentioned, which was leads. At ShoreTel, that was another thing — we took a lot of responsibility for helping our channel partners developing leads. Developing leads isn't just about going to tradeshows or doing advertising or PR campaigns, revamping the website or using Google Adwords programs.

Again, how well do you not only qualify those leads, but nurture those leads through the sales funnel? Most companies do not do this well.

At ShoreTel - during my time there of about a year - we generated about 10,000 leads. Can you imagine throwing all those over the fence to sales and saying, "Here you go?" How many are going to get followed up? Maybe 1,000. Right? In the course of a year. Or a couple thousand. There are going to be lots of wasted leads.

I saw some information that came from Sirius Decisions - a company that does some great benchmarking work in the marketing business. Basically, they indicated that 80 per cent of all leads aren't followed up on at all. Then another 80 per cent of the leads that do pass through in that first 20 per cent are not nurtured and not followed up on. Yet they end up buying, eventually, from your company — or of course worse, from the competition.

Being able to make sure that the salesforce is focusing on the leads that are ready to buy right now, and that the marketing function is taking the responsibility for the low-touch leads that need to be nurtured through the sales funnel is a major $\mathrm{MO}$ endeavor. It's very important that marketing finds ways to not only take that responsibility, but to automate that process as much as possible.

There are some great lead-nurturing solutions. We've done some work with a couple of companies, lately, on lead nurturing. Basically, they're able to keep a dialogue open and keep a communication flowing with their target audience - even in between the period where we contact them and they say, "We're not ready, yet. Call me in six months."
Fortunately, we've got the lead nurturing going on, so they think to call us, rather than our competition swooping in and getting lucky and calling them right at the right time when we're still not due to call for another three months.

MM: If I understand you then, Gary - you're saying that marketing and sales operations in the past have had a kind of antagonistic relationship.

GK: Marketing and sales are in conflict in many companies. Most channel companies have benefited from a sales operations function for some time, but $\mathrm{MO}$ is still a relatively new function. With increasing demands for accountability, these two functions unquestionably must work hand-in-hand to address the buying funnel and accomplish mutual organizational goals.

MM:You're saying now that with the increased pressure for greater transparency and greater visibility in terms of the sales pipeline and therefore projectable revenues.... as a function of the web having really exposed aspects of the buying funnel...MO has begun to systematize and organize itself in terms of a continuous process. You call that a buying funnel.

Sales operations has also now stepped up, in part, led by CRM. That has made the day-today activities of salespeople more transparent and more self-evident in terms of how many touchpoints were contacted and what the interactions were, and so on.

As these two sales and MO have begun to move closer and closer in terms of more seamless or integrated operations that are managing the buying funnel, you then start seeing the buying funnel as broken down into several stages.

The first common stage is "prospecting." The middle stage is "nurturing" and the last stage is "closing." You're saying that MO are now spending a lot more time understanding how to automate and put systems in place for prospecting. And perhaps most importantly, the nurturing process.

GK: That's right. That enables the sales people to be more effective.

We're seeing companies like Symantec, for instance, who recently named their VP of MO to be responsible for sales operations, as well. Sales and marketing alignment has been 
problematic in a lot of companies. It's not exactly a brotherhood.

Often, marketing is the stepsister. Sales are the king in many companies, anyway. We need to be sales' best friend. We need to get away from that antagonistic relationship, and we need to enable them to do their jobs.

One part of that in $\mathrm{MO}$ is to help align the company's sales process with the customers' buying process. That's a very important area of MO. We can understand — based on where things go wrong - where the train derails. We can start to understand whether there is a consistent pattern. In that case, it could be a messaging issue or a product issue. It could be a brand issue or a credibility issue.

If the process always stalls at the CFO level of the customer company, then you know that it's one of those things I mentioned before. If it continuously stops at different stages in the sales funnel, then you know it's probably a sales training problem, and that you need to train your people in a different way. Of course, marketing should be supporting sales in this area. MM: This comes back again to something that we had started to develop as the idea, in terms of a customer reference pipeline. It seems to me that a really good conversation with a customer who has successfully transited from a prospect to a buyer to a deployer — that process or journey reveals meaningful events in the buying and using process. That ultimately corresponds to touchpoints in your sales and MO.

GK: Well put!

MM:Yes. In the process of following a customer and also benchmarking or rating their willingness - the topics and the participation scenarios in terms of what they're willing to do and say and stuff like that, you're really kind of documenting the process of customer-making.

GK: That's absolutely right.

MM: That becomes a tremendous source of insight in terms of what works - what moves a buyer to a customer from a MO perspective as opposed to from a sales operations perspective. GK: That's right.

The one thing I didn't mention is this role of reaching out to the customer through the customer reference program. You not only develop great feedback about what you can say and who will cooperate in terms of marketing activity... and of course in terms of who might cooperate in terms of helping you win the next sale... But you also benefit from gathering incredible intelligence that you can pass forth to your R\&D group. And thus, participate in the innovation and the prioritization process for the MRDs.

MM: In your customer reference pipeline, you mentioned that there's a person who's more or less a stakeholder of that. They contact the partners and get introduced. They then start to build a database of people. What's then the nurturing process that goes on in a customer sales pipeline?

GK: I think at that stage, you're gathering information on what's interesting to them. You can do the same types of things with that customer that you would do with the sales lead.

You can make sure that they get new information as it comes out.

MM: That would be like newsletters and emails?

GK: You can do newsletters and e-mails. You can include your customers in marketing activities - actually make them part of your marketing plan. You can support your channel management to enable channel partners with go-to-market strategies.

At ShoreTel, for instance, we had somebody who was responsible for channel marketing. At least part of the time I was there. There was part of the time that I took on some of that role.

Basically, she helped those companies take a new ShoreTel offering to the market to their customers, by providing tools and so on. I think while that is considered a channel management function at the high level, there are things operationally that one can do to support that.

For example, you can help those companies get better terms - perhaps better volume deals from the company — or co-op funding or better Spiff type programs, based on their cooperation in the customer evangelism process. You can reward your customer companies that way.

MM: We were talking about the customer reference pipeline or the customer reference management system.

GK: That's right.

MM: Once you've identified the person and you've got a profile on them - you're doing a couple or three things. One is, you've got some sort of survey - a set of questions that you 
want customers to answer - that really reveal where they are in the process. Perhaps part of their position in a maturity model or process roadmap ...

GK: Yes. This is an ongoing type of survey that's done. Right?

MM:Yes.

GK: Every quarter, probably, these companies are reapproached. Especially those that are the most interested in being references in some way, shape or form.

MM: Some of the data that you're collecting really feeds your product innovation and product management roadmap in terms of wanted and needed features. Or things that are sub-optimal and broken and needing to be fixed. Or things that are missing.

It gives you an opportunity almost to create a customer advisory board. Almost an ad hoc customer advisory board.

GK: Yes. Very nice. Actually, that is an area that we focus on. Mike Gospe on our team has done some tremendous customer advisory board facilitation for some large companies and small companies alike - both in the US and in Europe. And the customer advisory board is a powerful vehicle to be able to understand the decision drivers for customers, and to thus prioritize what the company should do. That's a very good example.

MM: When you have a customer edit your value proposition, it becomes their value proposition. When you have a user or a customer edit your product roadmap, it becomes their product roadmap. It turns out that the editing function is one of those critical opt-ins to creating an evangelist.

GK: That's right. Because they have buy-in.

MM: More than buy-in. They have a personal sense of co-ownership in your success.

GK: That's right.

MM: You introduced this notion early in our interview. MO has shifted in large part because of the web. Earning and keeping the trust of customers now is a priority, whereas in the past, it may not have been.

GK: That's absolutely right.

MM: From an operational and tactical standpoint, creating a customer reference pipeline is really one of the first operational, tangible expressions of earning and keeping trust.
GK: Yes.

MM: It creates a feedback loop with your customer. If they've got a problem in your dashboard with a red or yellow light, that's attention. There's a whole remediation process that can take place. Right?

Then as we start to aggregate more and more of these, a certain number of these customers want to take the next step. They want to become an active member of the customer advisory board. Right?

It's a systematic way of having customers take co-ownership of the product, the product roadmap and therefore the success of the company.

GK: Yes.

MM: Could you then get into some of the operational aspects of creating and managing customer advisory boards?

GK: Well, I could. I don't know if I want to go super deep on that.

I think that one of the keys - and I don't think that every company does this...I think this is a basic premise for any type of audience where you're trying to get their input and alignment objectively — which I think a lot of companies miss.

If the CMO runs that process, it's probably sub-optimal. It's best to bring in an outside party, who will allow the agenda to flow.

I think that companies benefit most from bringing in professional facilitators to lead a customer advisory board. It will enable the CMO to listen very closely to the customer, without having to worry about the agenda of the meeting. I think that's the position that CMOs need to be in, if they're trying to both engage and gather information and facilitate, all at the same time. I think that's defusing.

MM:You're saying that fundamentally you need a neutral, independent third party to really hold the space and really maintain that collegial conversation among peers.

GK: That's right. And make sure that all the participants get to pipe in more or less equally. That's difficult to do.

Most companies will say, "I'll give you five minutes."

MM: It seems to me that in terms of the customer advisory board, you really need a strong facilitator - not the CMO. 
GK: Not the CMO; you need someone who doesn't have an agenda.

MM: Or has an agenda called, "Whatever it is that you want to share, or whatever it is you want to get, I'm committed to delivering that." GK: That's right.

Also, of course, the facilitator keeps track of time. He helps the group get to where they want to go at the end of the discussion and so on. MM: Another aspect it seems to me that goes on in a customer advisory board... There's some sort of CIO blueprint and/or a product roadmap. Those are the yin and yang of the same thing.

The product roadmap is, "Here's what we have today. Here's when we're going to have the next release. And here's what we're thinking about for the next release." Those are usually our technical capabilities, functions, feature sets and so on. They've not necessarily been socialized or have not gone through what I'll call the "solutioneering" process.

Right?

GK:Yes.

MM: Then a CIO blueprint is essentially how your customer typically looks at all of those technical resources in terms of the totality of his techno-business ecosystem.

It seems to me that on a customer advisory board, these two things start to sync up - the product roadmap with the $\mathrm{CIO}$ deployment blueprint.

On some of the customer advisory boards that I've participated in, a really strong facilitator then pulls out a set of scorecards by which to start quantifying the level of need and value of various feature sets. At the end of a customer advisory board, you have some pretty clearly understood and ranked product requirements that then become the priorities for engineering to develop.

GK: Yes.

MM: I've also seen customer advisory boards where a similar sort of thing takes place with respect to the post-deployment process. How do we take the kinks out of our service delivery system? That really becomes a 20/20 hindsight reflection on, "What's the optimal way of engaging customers, deploying it and ensuring success?"

I've also seen customer advisory boards where they have gone through the messaging and buying process. Specifically, "Here's how we'll talk about this. Here's our marketing collateral. Here's our website. Here's our PowerPoint Presentation deck. Here's our sales script. What we'd like you - our trusted customer advocates - to do, is to take us through the process of systematically eliminating all the Dilbert speak." To really have this expressed in keywords and phrases - in a manner that's natural, organic and resonant with how you experience the world.

GK: Absolutely.

I think one of the basic principles of a customer advisory board is that it's not a sales event. You can't treat it that way.

It's a business-level focus group, where the purpose is to discuss, debate and provide honest and direct insight and feedback on industry trends and business drivers.

That's the kind of feedback you want to get from your customers. Yes. It certainly can evolve into a technical discussion. But I think that the customers you've invited should be your most strategic customers. Otherwise, it may be a different type of session than a customer advisory board. It may be a technical advisory board with customers involved.

I think it's important to make that differentiation.

MM: Right. Then this leads into - naturally a user conference?

GK: User conferences are indeed wonderful things for some marketing folks, and this is kind of a sad statement, actually, since a user conference is the only time during the year that they see their customers.

MM: Yes.

I've participated in a number of user conferences. They fall into a few categories. One is, basically a three or four-dimensional brochure. GK: Yes.

MM: Now unfortunately, a lot of people just want to sit on the sales pitch and go, "Oh, yes. I want to buy that next." Or, "Gee. I bought that. But what else do I need to know about it?" So there's that.

Then there's the second kind of user conference - which really says, "At the end of the day, our products fit within a technical business ecosystem," that in other conversations we refer to as a "digital supply chain," or "digital value chain." 
GK:Yes.

MM: Really, it's about taking that CIO blueprint to the next level. Here's how all of this stuff plays together, interoperates and integrates. And here's what you need to know about how to make this part of a functioning and contributing capability in a digital supply chain framework.

Those really come from two very different perspectives, don't they? One is the sales pitch and the other really is about satisfaction assurance.

GK: That's right.

You know Michael, I think that it's really important to say that the agenda and the associated messaging content that's most successful is also enabled through a great MO process. That leads us into, "How is the brand governed? How are the messages developed? Are those messages developed specific to that target audience? Or are you just trying to throw the same message out to everybody?" All of these types of considerations.

In terms of how the company's positioned and how it's messaged to its different targets, a lot of companies don't do a very good job of making sure that they are customizing that messaging.

That gets into a brand governance issue. That, of course, is another area where MO really shines. There's so much cross-functional alignment effort that needs to occur, in terms of different groups in the company - from sales to the product group to customer support and so on - all speaking with one clear voice.

Then of course, as we were talking about before - you have to have the voice of the customer as a key component of what goes into that messaging and positioning of the company. If you don't have that, then there's a disconnect between what the company says and what the market perceives that they can really do and really deliver.

MM: Let me see if I understand, then. We've had this customer advisory board or this user conference. We're talking with customers who are somewhere in an advocacy-participation framework. That's the status in the customer reference pipeline.

Now we want to start summarizing that in terms of - first - how consistent is our brand voice? Does it have meaning?
Then secondly, the dance or interplay between our brand voice and our core value proposition. The brand is like the rhythm and base of the song, and the value proposition is more like the melody and actual words to the song - to use a metaphor.

GK: Yes.

MM:You want to really see not only everybody on the same page and singing from the same song, but are they in key? Are they harmonizing?

GK: That's right.

We were already into a customer advisory board conversion. Having talked previously about things like customer reference pipelines and sales pipelines and so on... Really, even in the front end of this, there's the whole thing, "How do you operationalize the message that you're getting out there" in support of the brand that's perceived by your market?

These things are all occurring synchronously with one another. Right? I just wanted to make sure that we emphasized that you're only going to be really successful on the customer advisory board or some other type of event if you have the right kind of brand governance process going on - that gets both the support of your internal stakeholders and the input and validation of your external stakeholders.

Does that make sense?

MM:Yes. Makes total sense.

In the marketing process, typically what I'll call the procedural campaign generally starts from an insight - a big insight. Or a new technology to go-to-market.

Then we go into the strategy-formulation process. There, we start to correlate. How do we position this? Where does it fit in the marketplace? What's the appropriate pricing service-delivery model?

GK: Let's assume we have a company. Usually companies start thinking of product right away. Product is very important. You don't have a lot without a product or a service.

But what most companies don't spend enough time on is the understanding of who they are as a company. I think it's even more fundamental than that. I think that companies that don't have a clear sense of mission and don't have a clear vision for where they are and what types of problems they're trying to solve and how they want to be seen in the world - 
if they don't understand their own value system or don't have agreement in vision, values and mission - it's a struggle all the time. We see this over and over and over again.

MM: Therefore, they have no North Star or center by which to start organizing processes and engagements for customers.

GK: That's right. Because - first - there's no agreed upon direction. People go different directions, based on their own interpretation of it. Secondly - they can't get any consistency. Right? You can't get to a point where marketing is becoming more scientific and more predictable if you don't have consistency in how you're executing to reach those goals.

I think that a lot of companies never deal with those issues. They're moving so fast that they don't have time to sit down and agree on these things. Or they believe that. They just start running right away.

I think that's probably caused the most companies to go out of business. It isn't because they didn't have a great product. A lot of companies had great products and still went out of business. It's because they didn't know who they were as a company, and where they were going. Or somebody knew, but they couldn't get agreement from the other stakeholders, so they didn't have the support they needed.

What's the knee-jerk reaction if you don't have support? It's to fire everybody around you, maybe. Then to bring new people in. But if you still can't convey what it is that you're trying to accomplish - then you're only going to reinvent that situation again.

It's like an individual who has a drinking or drug problem or some other behavioral problem. The person is only really going to be receptive when they're in enough pain and when they're having enough consequences in their life that they feel they need to do something different.

MM: Let's just characterize that as the domain of leadership. In the domain of leadership, it all runs downhill from the top. If you've got a fundamental breach or a fundamental discontinuity in leadership, there's no amount of marketing that's going to fix that. Right?

GK: There's no amount of marketing that's going to fix that.

MM: There's no amount of innovation that's going to fix that.
GK: The best that MO might be able to do is to survive, of course. And maybe shine a spotlight on it. Something has to intervene. Right?

MM: Usually the market intervenes.

GK: Well, yes. The market is, of course, the most powerful source. As long as the company continues to be successful, even if they are operating dysfunctionally - they aren't going to experience the pain.

MM: Let's stipulate in this framework that I'm laying out here, that we have leadership. It's functioning and it's vibrant. They have a clear message and a clear set of values. They're doing their best to bring about the success of the enterprise. Let's just stipulate that for a moment. GK: Sure.

MM: In the traditional formulation, you have what I'll call the insight-driven marketing campaign.

The "big a-ha" is either that we've got a new capability that we need to figure out how to go market and sell. Or we've done some research and we go, "Wow! There's this unserved market need." Right?

GK: That's right.

MM: In some cases, that unserved market need requires some new engineering. And in some cases, it's just really about remixing it into a new configuration - branding it, marketing and selling it.

GK: Yes.

MM: That last scenario we'll find with larger companies that deal with incremental innovation and large installed bases. Typically you have a big insight - the "a-ha." Then you go into formulating a strategy. At the end of the day, that's really, "What do we have that we can align and focus, to go after that opportunity?"

Then, "Do we have enough budget to take that to market? Do we have a go-to-market program that can succeed?"

At that point, it then gets distilled into a marketing or launch plan or a campaign. Then that marketing plan starts to precipitate creative briefs that go off to our various creative partners. There's a print-broadcast part and an online part. There's an e-mail marketing and interactive part. There might be a direct mail part or a publicity PR promotions part. There might be an event-tradeshow-roadshow-seminarwebinar part. There's probably a part that reaches 
into the sales operations in terms of, "Here's the new deck and here's the script that goes with this. Here's the telemarketing call center part" in terms of scripts, websites and stuff to refer people to. Right?

GK:Yes.

MM: Each one of those stakeholders or partners who are part of the marketing operation gets a creative brief. Right? They go off and do what they do. Then, come the launch, we're going to paint the town red. It all hits. Right?

So the print piece, the online, outdoor, direct mail and the e-mail marketing piece. The call center. They're all singing from the same songbook, singing in key and it's all good. Right?

GK:Yes.

MM: That's the traditional marketing procedure. It tends to be very linear. And it tends to be that once you've fixed on a marketing strategy, it's drill-and-kill.

GK: Yes.

MM: Two things I'd like you to comment on. One is that as the web and self-directed customers have really begun to drive the buying process; oftentimes you have customers who are engaging potential buyers before they've had time to bake the procedure. Right? Before they got their act together.

GK: Sure.

Microsoft's a classic example of that, aren't they? They seem to overcome things that other companies wouldn't overcome. Nobody else can quite follow that example and succeed.

MM: There are a couple. Apple might fall into that category.

GK: Apple is definitely an interesting company. Although you wouldn't have said that seven or eight years ago with Apple.

MM: As an actual matter of fact, I'm on record of having said that 10 years ago.

GK: You did? Well — hey — how about that? You're a better soothsayer than most of us.

MM: No - it was a function of our extensive work with the third- and fourth-party developers for content. Seeing how the efficiencies of Apple technologies were so much superior to those of Microsoft technologies. But that's a story for another day.

GK:Yes.

MM: But MO has to now deal with 360-degree engagements. Right?
GK: Yes.

MM: From a MO perspective, that fundamentally means that the big launch program is really kind of secondary to the primary soft launch and micro-launch. Right? GK: Absolutely.

I would say that one of the beauties of having the kind of mechanisms that we have on the Internet these days is that you can actually do a lot of testing before you spend a lot of money on that large launch. Through Pay -Per Click and other types of things. You can change up your message easily. You can be running different messages at the same time.

MM: From an organizational perspective, that basically means that a marketing operation now must have a much more agile, creative process and a much more agile sourcing process or operation for all of those micro-launches and soft launches that are part of the engagement strategy.

How has marketing procurement and strategic sourcing evolved to accommodate the new demands of 360-degree engagement strategies and brand interactions?

GK: Okay.

I think that there are opportunities in marketing to have quick wins. MO can start earning its stripes in terms of cutting back on waste. I think there's a tremendous amount of waste going on in the supply chain in the purchasing process.

We've heard stories of companies just standardizing on one paper supplier or one type of paper, to save several million dollars just like that. There are all sorts of opportunities for wins.

There are now companies out there that are still relatively unknown, I think, to most companies. If you're spending a lot of money on print, for instance, they know in your geographic area and in your supply chain who's under-capacity - and thus, who would be most open to negotiate a better deal.

Companies are beginning to realize that there are a lot of savings to be had in terms of some of the fundamental marketing expenses that they incur all the time - print being one example. In the buying process, to the degree that you can partner with companies that are focusing on making the supply chain more efficient... To the degree you can partner with your own purchasing function... We're going to have a 
case of the right hand knowing what the left hand is doing more - and benefiting from expertise and operational discipline that's been put into place by others. Either internally or outside the company.

I think that's a great area for MO to get some quick, easy wins.

MM: One of the things that all of these soft and micro-launches do is to iteratively gather more and more information, feedback, insight and intelligence about the voice of the customer.

GK: Absolutely.

MM: From an operational perspective, how have you seen clients and/or partners really systematize the development of the voice of the customer? In terms of specialized databases, specialized data models for characterizing customers and so on?

GK: With that, it's still an evolving area. It isn't always something that's under the control of marketing. My experience goes back to about 15 years ago, working with Sun University which is a training and education group of Sun Microsystems. I was a facilitator for their Voice of the Customer/Voice of the Employee program.

In that day and age, Sun had a fairly lowtrust environment. One of the things they did was interesting at that time. They had a bunch of Macintoshes networked together so that people could do things like brainstorming and voting and other types of collaborative things. In the same room, but anonymously. That was 15 years ago that companies were starting to employ that - using early groupware types of solutions.

Today, I think we're seeing more and more effort to try to better predict what a customer is going to do. This whole evolving area of predictive analytics - in terms of trying to understand from the past and present what the future might look like... It's certainly very applicable to the customer area in terms of, "How are you going to be able to figure out what a customer's lifetime value is?" How would you calculate that if you can't forecast?

That really ties right into the sales funnel issue. And even before the sales funnel, to the planning process. I'm not sure if I'm answering this question very well. You'll ask me another question if I haven't.
MM: Well, as we think about the voice of the customer, the Voice of the Customer had its roots in the quality management Six Sigma and Lean Six Sigma discipline.

In that framework, they were defining "quality" in terms of deviations from an idealized norm, ie... Defects per thousand, hundred-thousand, million, billion, etc. Hence the term Six Sigma.

GK: In terms of six nines of reliability.

MM:Yes.

The Voice of the Customer then was the social context around the meaning of one class of defects or variations versus another.

GK: Right.

MM: The Voice of the Customer in the quality circle has a very tangible, concrete operational database framework. In MO or in overall business management, what kinds of systems have you seen that really systematize the voice of the customer?

GK: I think that first of all, we've seen Six Sigma, Lean and Lean Six Sigma being implemented in $\mathrm{MO}$ in trying to accomplish different types of goals. Six Sigma focusing a lot on processes and on eliminating errors and that type of thing - and Lean tending to focus more on the big-picture stuff, and eliminating waste.

There are companies like Computer Associates - where our advisory board member Steven Sugar formed the MO function - that had specific focus in that area. We know that there are companies over here even in the Silicon Valley - like Intuit and Seagate, that are implementing, for example, Six Sigma in their marketing function as part of a greater corporate initiative.

I think first and foremost, you have these kinds of super process strategies or approaches that are being applied to marketing. I will say that so far, there's a lot of learning to be had in this area. A lot of people are coming into marketing who don't have experience in marketing. They are, for example, Six Sigma black belts - but they're coming in with enforcement or policing mentality. Unfortunately.

I think that companies are discovering that that doesn't work so well. So there've been some lessons as far as that's concerned. I heard from a colleague of mine at Sprint, and I've also 
heard from Cisco and Nortel, that the policing approach didn't work for them.

They are putting these super-processes in place. But they're doing it from a corporate standpoint. Oftentimes, that kind of leaves the regions and business units out on their own. The challenge is how to provide the right enablement and the right brand governance from a corporate-centralized standpoint and still give the right level of authority and support to your business units.

Ultimately, they're the closest to the customer, and they understand what's going on in that particular scenario. There are still a lot of challenges there, Michael.

What else have I seen? I have seen processes put into place to better train people how to elicit the right type of customer-appropriate behaviors, even when they have no authority over those people who touch the customer. I know Lynn Hunsaker on our team does some work specific to that, in teaching managers how to incentivize the right kind of customer-facing behaviors. Even when relying on people who are not within one's scope of authority.

In MO, I think we have a lot of challenges like that. There are a lot of people we need to rely upon who we have no authority over, whatsoever. That's another example of a type of voice of the customer application in MO.

MM: I think perhaps what we should do is kind of circle back to a point that you made earlier. That is, when we look at MO, we're looking at a fairly sophisticated ecosystem that has a lot of moving parts and a lot of ambiguity. The cycle times in those operations continue to accelerate.

As a function of having to get more stuff done more quickly, many senior leaders in marketing now start to ask themselves, "How can we start to put in systems, processes and accountabilities to make this easier, more efficient, more effective, more transparent and more agile?"

GK: And how can we do it within the span of my 26.8 months' tenure. Right?

MM: Right.

GK: That's a kind of basic conflict that I think we all have to deal with. It's a lot easier to get these initiatives moving when your CMO has been around a while and built some trust with the C-team. But oftentimes, these same people who might be moving forward already have their résumés out on the street looking for their next jobs.

MM: Right.

I'd like to have you speak to the ideal skill sets in terms of basic, intermediate and advanced. The ideal skill sets of not the CMO, but the aspiring $\mathrm{CMO}$. The person who really corrals and really manages this whole marketing operation will be in touch with analytics and with content strategies, with marketing procurement, and in the alignment of marketing and sales operations.

GK: Sure. Well really, when you're starting at the fundamental level, usually the type of thing that a company is looking for from somebody in $\mathrm{MO}$ is the ability to handle the financial side of things. The budgets and so on.

To start thinking about measurement, but usually in a fundamental way. Maybe create the first dashboard. It may be somebody that can roll out a CRM deployment or make it more effective.

A lot of companies, for example, are rolling out Sales Force. That might be something that the MO person either does or tries to provide more optimization of that particular resource to marketing and sales.

Basic marketing services - things like some of the vendor management types of things - or creative or production. Those types of basic services are often part of the skill set of somebody who's coming in to run the MO.

Oftentimes the first person in the door is either somebody who brings a financial analytics capability into the marketing function, or somebody who's a very strong project manager who understands a lot of different things.

There are some companies that started with somebody that actually had IT experience. I'm aware of at least one well-known Silicon Valley company that initially focused on the systems when launching its MO function. The initial MO director actually came from the IT world. Now they've moved on from that approach and have an MO leader in place who's more business-oriented. I don't know if they would've taken the same approach if they had the opportunity to do it again. Starting with systems or a dashboard first always leads to having to go back to the fundamental business issues that MO is trying to address. Companies have learned the hard way that you don't start with the tools. 
As you get further along into what we call expanded $\mathrm{MO}$, then you're starting to think about people who can put campaign automation into place. Beyond the CRM type of capability. Other types of marketing - specific Sales Force automation - marketing automation types of solutions. From campaign automation to MOM and MRM and DAM.

At this stage, you're starting to develop more sophisticated thinking about metrics. Especially metrics aligned to specific marketing programs. Starting to be able to map processes and capturing best practices. To address some of the knowledge-management issues. Starting to be able to find incentives to elicit the right kind of behavioral alignment.

When you get really sophisticated, you might have people who are bringing in Lean or Six Sigma (or a combo) capabilities or have a change management background. They're trying to develop the competency of the company and beginning to look at metrics. Not just as a siloed type of measure that are specific to a program, but cascading to whatever the enterprise strategic agenda is.

They may be putting in a marketing governance process. Maybe they can bring some expertise in spend management in terms of not just a budget, but more of a portfolio type of approach. Looking at analytics - maybe more so in a predictive way. Really, driving marketing into more of a strategic management function than a tactical function.

Those are both areas of focus and areas of subject-matter expertise that one might bring in. Usually the MO leaders that I think have been most effective, they have experience in a number of these areas, but more than that, they have a very clear picture and a very clear vision of what's possible.

They also know - if they don't have something - where to find it.

MM: Great.

This sounds like a great place to wrap up. Again, thank you so much.

GK: My pleasure. 